\title{
Vidas Errantes e Alcoolismo: Uma Questão Social
}

\author{
Euripedes Costa do Nascimento ${ }^{2}$ \\ José Sterza Justo \\ Universidade Estadual Paulista/ Assis
}

\begin{abstract}
Resumo
O fenômeno da errância, impulsionado por motivos sócio-econômicos ou mesmo por razões pessoais, traz consigo profundas transformações no plano psicossocial. A presente pesquisa se propôs a investigar as razões que levam os "trecheiros" à ruptura com a vida sedentária e o papel que o alcoolismo exerce nesse processo de deserção. Foram entrevistados doze sujeitos que fazem uso de bebidas alcoólicas, albergados numa Instituição Assistencial da cidade de Assis, SP, sendo as entrevistas submetidas, posteriormente, a uma análise de conteúdo. Os resultados mostraram que a morte dos pais, os conflitos familiares e o desemprego têm sido um dos principais motivos para a ruptura com o sedentarismo. O uso do álcool, no "trecho", é atribuído pelos próprios sujeitos à necessidade de "esquecer problema", maior encorajamento e apaziguar conflitos remanescentes, em geral, conflitos afetivos que possuem como epicentro a infidelidade conjugal.

Palavras-chave: Alcoolismo; errantes; família; infidelidade conjugal.
\end{abstract}

Roamers Lives and Alcoholism: A Social Question

Abstract

The roving phenomenon moved on by personal, social or even economical reasons brings along deep changes in the psychosocial plan. The purpose of this research was to investigate both the reasons that take the roamers to the rupture with the sedentary life and the function that the alcoholism has in this desertion process. Twelve people addicted in alcoholic beverages, lodged
lon from an Assistential Institute in Assis, São Paulo State - Brazil, were interviewed. Afterwards, the interviews were submitted to a contend analysis. The results showed that the parents' death, the familiar conflicts and the unemployment have been the main reasons for the rupture with the sedentarism. The use of alcohol in the trajectory has been attributed, by the subjects, to the need of forgetting problems, getting more courageous and pacifying remaining conflicts, usually affective conflicts which has the marital infidelity as the epicenter.

Keywords: Alcoholism; roamers; family; marital infidelity.

O alcoolismo tem sido uma das maiores preocupações da saúde pública no mundo, estando associado a diversos outros problemas como: mortes no trânsito, desentendimentos familiares e afetivos, separação de casais, sendo, também, companheiro inseparável de homicídios, espancamentos de crianças e mulheres, deserção do trabalho, da escola, etc.

São numerosas as tentativas para se compreender o alcoolismo. Alguns autores acreditam que suas causas estão associadas a um complexo conjunto de fatores biopsiocossociais (Bertolote, 1997; Vaillant, 1995/1999).

$\mathrm{Na}$ esfera biológica, fatores hereditários e predisposição ambiental são freqüentemente mencionados como uma das possíveis explicações para o consumo e dependência do álcool. Cloninger (1987) em seu trabalho com gêmeos, utilizando o método dos filhos adotivos, concluiu que o alcoolismo, em alguns casos, se deve à herdabilidade gênica e, em outros, à predisposição ambiental. Desta forma, dependendo do

Endereço para correspondência: Rua Três de Maio, 02, B. Itaú, 37900144, Passos, Minas Gerais. E-mail: ecnascimento@hotmail.com ${ }^{2}$ Projeto financiado pelo PIBIC/CNPq lugar que o indivíduo ocupa numa determinada cultura, bem como dependendo das características do ambiente vivido na infância, ele poderá ou não desenvolver o alcoolismo em sua personalidade, conforme acrescenta Vaillant (1995/1999).

Dentro de uma perspectiva sociocultural, vários trabalhos têm sido realizados na tentativa de compreender o consumo de bebidas alcoólicas. Muitos autores apontam que as influências ambientais constituem um fator preponderante para a instalação de futuros e/ou precoces alcoolistas, conforme verificaram Araújo (1995), Braga (1977), Jorge e Ferraz (1981), Silva e Cursino (1995) e Sonenreich (1971). Como principais influências do ambiente, destacam as pressões dos amigos, bem como induções do meio familiar, principalmente por parte do pai na infância do indivíduo ao oferecer alguns goles com o intuito de induzi-lo a "hábitos mais masculinos".

Outros problemas também aparecem na literatura científica vinculados ao abuso de álcool: perdas múltiplas de emprego, reclamações da família, dos amigos e problemas conjugais como verificaram Bertolote (1997), Braga (1977), Castro e Silva Filho (1993) e Vaillant (1995/ 1999). 
$\mathrm{Na}$ esfera psicológica é possível localizar, ainda, outro conjunto de fatores associados ao uso do álcool. Certos traços de personalidade aparecem vinculados ao alcoolista como por exemplo: regressão emocional, imaturidade instabilidade, ansiedade, insegurança e fraqueza do ego como ressaltaram Van Kolck, Tosi e Pellegrini (1991) Sonenreich (1971). Trata-se, ainda, segundo Van Kolck e colaboradores, de sujeitos dependentes, tímidos e fugidios, com medo de tomar iniciativas e de assumir responsabilidades onde a fantasia pode se apresentar como fonte de satisfação ou como refúgio possível da frustração das aspirações intelectuais. Deste modo, o álcool funcionaria como um mecanismo de fuga do indivíduo devido ao seu sentimento de inadequação, encoberto por ideais de grandeza, certo perfeccionismo e exibicionismo, apresentados face à sua auto-imagem negativa. Uma outra caraterística do alcoolista é a sua incapacidade para assumir responsabilidades num relacionamento amoroso permanente, segundo Sonenreich. Castro e Silva Filho (1993) apontam, também, que em decorrência das complicações psíquicas como a irritabilidade, agressividade, prejuízo na compreensão e alteração da visão de mundo, o alcoolista vai provocando dificuldades no seu relacionamento familiar que se vão agravando com o tempo.

Para Alonso-Fernandez (1991), os alcoolistas apresentam os seguintes traços em comum: a vivência da solidão, a desesperança e a imposição do presente anônimo e passivo. No tocante à vivência da solidão, Alonso-Fernandez chama a atenção para a condição de isolamento do sujeito desde a infância devido à omissão do "outro" em oferecer-lhe amor. Deste modo, "outro" é visto pelo alcoolista como um ser onipotente e ameaçador que pode e quer destruí-lo, desencadeando, assim, um conjunto de reações emocionais que nutrem seu sentimento de inferioridade física, psicológica e intelectual, fazendo com que o alcoolista recorra sempre à insinceridade como mecanismo de defesa na sua convivência cotidiana. O sentimento de solidão é devastador e insuportável porque assenta-se no aniquilamento de suas esperanças decorrentes da frustração afetiva.

Quanto à desesperança na personalidade de alcoolistas, ela se funda nos fantasmas de insucessos anteriores e no temor de novas frustrações no presente, fazendo com que o indivíduo sinta que seus projetos de realização pessoal estão condenados antecipadamente ao fracasso, pelo fato de seu passado resguardar muito mais decepções e desenganos do que conquistas. Predomina um estado de tédio e indiferença no qual espera-se nad da vida. Essa indiferença ocorre pela ausência de tolerância às frustrações, remetendo o sujeito ao mecanismo de repressão como forma de defesa por não suportar as tensões emocionais produzidas pela pressão das próprias necessidades individuais.

O alcoolista passa, então, a viver estagnado no presente anônimo e passivo sem dispor de perspectivas planificadoras que o direcione ao futuro, a um sonho de prosperidade, sujeitando-se à neutralidade e se aprisionando ao estado de desesperança-desengano puro que, em alguns casos, pode até culminar em atos suicidas.

Melman (1993) interpreta o alcoolista como um sujeito marcado por uma insatisfação constante consigo mesmo devido a sua não realização pessoal na sociedade. O sujeito procura no álcool o refúgio para alcançar sua satisfação, pois, sua existência se apresenta, na realidade, permeada por uma sensação de insuportabilidade carregada de sofrimento.

Num outro trabalho Melman (1992) acrescenta, ainda, a dependência relativa do alcoolista em relação à figura feminina da qual espera sempre a satisfação perfeita, absoluta. Nesse sentido, Melman aponta que “(...) o discurso do alcoolista se modula por uma submissão particular ao lugar de seu exclusivo endereçamento: à mulher, enquanto detentora e distribuidora de um gozo cuja totalização seria para ele sempre recusada ou dissimulada" (p.16). O autor comenta, ainda, que o que parece fazer falta ao alcoolista é o reconhecimento e o respeito dentro da própria constelação familiar.

Em nossa pesquisa sobre o fenômeno da errância na sociedade contemporânea, constatamos, preliminarmente, que o uso do álcool é bastante acentuado entre os "trecheiros". O "trecheiro" é aquele sujeito que sobrevive do trabalho volante e temporário ou da mendicância, transitando de uma cidade a outra, caminhando à pé pelas estradas ou se deslocando com passes de viagem concedidos por entidades assistenciais. A vida do "trecheiro" é tipicamente marcada pela impossibilidade de estabelecimentos de vínculos afetivos estáveis, pela deserção de toda e qualquer malha da rede social, pela pobreza extrema, pelo desamparo e o desenraizamento completo de qualquer solo geográfico-social-psicológico (Justo, 1998). Entre os mendigos, o uso do álcool está associado à necessidade de vencer a timidez, adquirir maior comunicabilidade, conquistar coragem e fugir dos problemas atuais em função dos sentimentos de pessimismo e conflitos em que vivem (Braga, 1977).

Segundo Justo (1998), predomina na vida errante o estreitamento da socialidade e o enfraquecimento dos relacionamentos interpessoais. Apesar do isolamento social, parte dos "trecheiros" mantêm algum tipo de vínculo com os familiares e desejos de retorno à vida sedentária. 
Ainda segundo o autor, as mudanças ocorridas no plano social, econômico e político, comumente chamados de globalização, impulsionam o indivíduo a grandes movimentações impedindo sua fixação em territórios psicossociais estáveis. Desta forma, o sujeito é estimulado a desertar da vida sedentária e buscar no nomadismo os meios para a sua sobrevivência.

Snow e Anderson (1992/1998) apontam, ainda, que o desemprego, a falta de apoio familiar e as desavenças conjugais são os principais motivos que levam os sujeitos a romperem com a vida sedentária. Os autores acreditam que a fragilidade dos vínculos sociais se origina principalmente nas circunstâncias sociais precárias em que esses vínculos se formam e se mantêm. São sujeitos colocados fora das disposições estruturais de um dado sistema social, ou que voluntariamente se afastam dos padrões de comportamento dos membros que têm status e função dentro daquele sistema.

Merton (1968), citado por Snow e Anderson (1992/ 1998), considera a questão da vida errante como uma estrutura social anômica. Segundo esse autor, a associalização decorre da falta de capacidade do sujeito para competir na sociedade em função de repetidos fracassos no mundo social. Snyder (1954) compreende o alcoolismo como uma conduta desviante e, nesse sentido, nos dizeres do autor, os alcoolistas são pessoas anômicas - desorganizadas, vazias, angustiadas, compulsivamente independentes e que desconhecem toda autoridade.

Castel (1995/1998) ao analisar a modernidade a partir da instituição do salário, considera que a produção do individualismo, mediante a retirada de proteções sociais, tem sido um dos principais agentes causadores da desfiliação e aponta que o colapso do desemprego vem acompanhado da ausência de relações sociais mais amplas. Conforme Castel, o enfraquecimento da condição dos salários se dá em função da substituição da rigidez do trabalho pela flexibilidade das tarefas devido à transformação da sociedade salarial em sociedade de indivíduos autônomos e independentes.

Deste modo, a competitividade na dinâmica atual da modernização leva a uma precarização do emprego e ao desemprego, tendo como conseqüência o surgimento de uma sociedade de trabalhadores sem trabalho, não integrados e sem dúvida não integráveis como o pertencimento a uma sociedade que forma um todo de elementos interdependentes. Dificilmente podem ser considerados pelo que são, pois sua qualificação é negativa (Castel, 1995/1998). Trata-se, então, de uma desfiliação social cada vez maior daqueles com pouca ou quase nenhuma qualificação profissional provocando o que autor considera de individualismo negativo.

Nesse sentido, parece que o mundo social dos excluídos e dos errantes constitui uma dessas subculturas limitadas. É um mundo social que não é criado ou escolhido pela grande maioria dos sujeitos, pelo menos não inicialmente, mas para a qual a maioria foi empurrada por circunstância além de seu controle (Snow \& Anderson, 1992/1998).

O alcoolismo entre os "trecheiros" pode ser tomado como uma das expressões mais radicais desse fenômeno na sociedade atual. Aí encontra a pobreza, a solidão, a desterritorialização sócio-geográfica do sujeito e tantas outras condições próprias dessa sociedade.

Levando-se em consideração a alta incidência de uso de álcool entre os errantes, este trabalho teve por objetivo investigar as razões que levam esses sujeitos à ruptura com a vida sedentária e o papel que o alcoolismo exerce nesse processo de deserção.

\section{Método}

\section{Participantes}

Foram tomados como participantes dessa pesquisa, doze "trecheiros", do sexo masculino, que fazem, assumidamente, uso de bebidas alcoólicas. A coleta de dados foi realizada junto ao Cetrem (Centro de Triagem e Encaminhamento Migrante) da cidade de Assis, S.P. Trata-se de uma Instituição Assistencial responsável pelo recolhimento de toda a população migrante que passa pela cidade: desempregados em busca de trabalho, mendigos, pessoas em busca de assistência médicopsicológica e outros.

\section{Instrumentos e Procedimentos}

Esta pesquisa utilizou uma entrevista estruturada, mediante o consentimento prévio do sujeito para a utilização de um gravador. O roteiro de entrevistas foi composto por dois blocos focalizando os seguintes temas:

Bloco I - Nesse bloco, as perguntas elaboradas tiveram como objetivos principais, delinear os motivos que levaram o sujeito ao processo de ruptura com a vida sedentária e o sentido da vida no "trecho". Foram abordados temas como: tempo que vive no "trecho", as vantagens e desvantagens, comparações entre o modo de vida antes e depois da deserção, relacionamentos sócioafetivos, as rotas percorridas, os vínculos familiares e as regras que se estabelecem no "trecho".

Bloco II-Este bloco teve por meta explorar as questões referentes, exclusivamente, ao alcoolismo, procurando 
investigar os motivos, as causas e influências que levaram ou ainda levam o sujeito à ingestão alcoólica, como, também, conhecer as suas perspectivas futuras. Inclui ainda o levantamento de relacionamentos sociais e afetivos estabelecidos antes do processo de ruptura, relacionamentos esses associados ao trabalho, família e vida afetiva, especialmente no tocante à vivência da fidelidade e infidelidade, conforme ilustra a Tabela 1.

Após a coleta dos dados, as entrevistas gravadas foram transcritas na íntegra e submetidas, posteriormente, a uma análise de conteúdo proposto por Bardin (1979). Tal método consiste em uma leitura flutuante do corpus (préanálise), separação e identificação dos temas abordados em unidades de sentido (análise temática) e agrupamento dos temas em categorias e subcategorias. A aplicação das entrevistas durou em média, trinta minutos, aproximadamente. A idade dos entrevistados variou de 24 a 53 anos e o tempo no "trecho" de seis meses a 28 anos, conforme ilustra a Tabela 2.

\section{Resultados}

Dividimos os resultados em dois blocos acompanhados de suas respectivas categorias. Desse modo, no Bloco I os temas emergentes foram agrupados em três categorias gerais: a) os motivos de escolha do trecho; b) estilo de vida; c) vida no trecho. No Bloco II, os temas referentes ao alcoolismo foram agrupados em duas categorias gerais: a) o uso do álcool, e b) perspectivas futuras.

Tabela 1. Roteiro de Entrevistas

\begin{tabular}{l}
\hline Bloco I \\
\hline 1. Quanto tempo faz que você está no trecho? \\
2. Como era a sua vida antes de entrar no trecho? \\
3. O que te levou a escolher o trecho? \\
4. Quais são as rotas que você percorre no trecho? \\
5. Quais são os valores, as normas e algumas leis no trecho? \\
6. Quais são as vantagens e desvantagens no trecho? \\
7. Como você sobrevive no trecho? \\
8. Compare a sua vida anterior e a do trecho? \\
9. Você tem intenção de voltar à vida sedentária? \\
10. Você ainda possui algum tipo de vínculo com sua família? \\
\hline Bloco II \\
\hline 11. Que idade você começou a fazer uso de bebidas alcoólicas? \\
12. Como foi seu primeiro contato com o álcool? \\
13. Havia outras pessoas que bebiam na sua família? \\
14. O que te levou e leva até hoje a fazer uso de bebidas alcoólicas? \\
15. Como você consegue a bebida? \\
16. Que tipo de bebida você utiliza? \\
17. Na sua vida você já teve alguma desilusão amorosa? \\
18. Como é seu relacionamento com as mulheres? \\
19. Você já traiu ou foi traído por uma mulher? \\
20. Você acha que consegue parar de beber? Por quê? \\
21. Você tem alguma noção sobre o tempo no trecho? \\
22. Existe alguns vínculos sociais e afetivos com o uso do álcool no trecho? \\
23. Você tem algum sonho que queira realizar na sua vida?
\end{tabular}

Tabela 2. Idade dos Participantes e Tempo no Trecho

\begin{tabular}{ccc|ccc}
\hline Participante & Idade & Tempo & Participante & Idade & Tempo \\
\hline 1 & 24 & 06 meses & 7 & 37 & 13 anos \\
2 & 24 & 07 anos & 8 & 38 & 05 anos \\
3 & 26 & 05 anos & 9 & 41 & 15 anos \\
4 & 36 & 02 anos & 10 & 46 & 10 anos \\
5 & 36 & 06 anos & 11 & 49 & 28 anos \\
6 & 36 & 14 anos & 12 & 53 & 18 anos \\
\hline
\end{tabular}

Psicologia: Reflexão e Crítica, 2000, 13(3), pp.529-538 


\section{Bloco I - Motivos de Escolha no Trecho}

As razões apontadas pelos sujeitos para a deserção da vida sedentária, parecem estar relacionadas com a desestruturação da constelação familiar e afetiva, permeadas por desavenças e pela falta de trabalho. Os relatos apresentados pelos sujeitos nessa categoria geral permitiram-nos analisá-los em duas subcategorias:

Conflitos familiares: os desentendimentos com os pais e as desavenças no núcleo familiar - brigas com a esposa e filhos - é um dos principais motivos apontados pelos sujeitos para a ruptura com a vida sedentária e início no "trecho". Parece, portanto, que as relações familiares ocupam um papel importante na vida desses sujeitos. Exemplos:

"Trabalhava, tinha minha mulher, minha filha, dai en briguei com a minha mulher... discutimos e nós separemo, né. Daí voltei pra casa e aí não deu certo, também, daípeguei e sai..." (Participante 3).

"Ai, me separei oito anos depois, tenho duas filhas, tenho uma casa em São Paulo que deixei para as filhas, né, aí... depois da separacão, segui meu rumo, trabalhar um pouco numa cidade, outro pouco noutra e assim vou andando..." (Participante 5).

Morte dos pais: um outro motivo encontrado nos relatos dos sujeitos associado a sua iniciação no "trecho", referese à perda de suas referências sócio-afetivas no núcleo familiar originário. Tais perdas, culminam na falta de um lugar fixo para viver, agravando a condição de pobreza extrema decorrente do desemprego que se sobressai como um fator preponderante no processo de deserção. Exemplos:

"Um dos motivos é a necessidade. Depois que parti pro trecho, que eu saí da minha família... ai o motivo mais é trabalho e procurar uma luta... eu andava bem com minha familia, depois teve outras desavenças e euperdi meu pai e minha mãe" (Participante 5).

"(...) foi naquele tempo que eu trabalhava, né, depois perdi minha mãe, meu pai e fiquei desgostoso, sem ter lugarpra morar" (Participante 4).

"Foi a separacão da mulher, foi ter brigado em casa, né, com meu pai e saí correndo de um lado e outro... meus pais moravam em Santos. Meu pai é falecido e minha mãe também. Meu pai morreu aqui no Paraná e minha mãe morreu atropelada em Santos" (Participante 3).

\section{Estilo de Vida}

Essa categoria nos permitiu comparar como os sujeitos conduziam suas vidas antes e depois de se evadirem para o "trecho". Questões relacionadas ao sedentarismo estável como trabalho diário e vida afetiva, marcam profundamente a trajetória de vida desses sujeitos, como mostra as seguintes subcategorias:

Antes: os sujeitos nos relataram que suas vidas antes de se iniciarem no "trecho" foram marcadas pela fixação social, seja no núcleo familiar ou nas relações afetivas com esposas e filhos. Muitos possuíam algum tipo de trabalho fixo e residência, e outros, pela desqualificação da mãode-obra, um trabalho volante e sazonal. A vida de antes é percebida por eles como razoável e suficiente em detrimento da atual. Exemplos:

"Ab! Rapaz, antes eu tinha uma vida boa, sabe? Não é falar assim... vidona, boa assim que nem muitos ricacos, mas uma vida assim, normalizada, né meu. Tinha a minha casinha de morar, essas coisas... Trabalhava, chegava à tarde, ter seu lugarzinho pra ficar, tomar seu banho numa boa, televisão pra assistir, tudinbo" (Participante 4).

"Eu já tive carro, uma serralheria... Mas eu tenho chance, voltando agora pra Londrina eu consigo dar um rumo pra minha vida... procurar um serviço e tudo mais... e sair dessa vida que não dá certo" (Participante 3).

"Olha, antes en trabalhava de vigilante bancário, né, trabalhei numas firmas e sou músico, tecladista... A vida de antes era digna do ser bumano que eu sou" (Participante 10).

Depois: O cotidiano do "trecho" é visto pelos sujeitos como difícil, instável e insuportável em função do desamparo social ao qual estão submetidos, da falta de trabalho regular e das incertezas e inseguranças que cercam o provimento das necessidades básicas: alimentação, agasalho, abrigo. Exemplos:

"Vantagem? De jeito nenhum, não tem vantagem nenhuma... falta de serviço, falta de comida, de lugar pra dormir, tudo isso, né? É geral, não dá nem pra explicar" (Participante 7).

“(...) só tem desvantagem, não arruma serviço fixo numa faz̧enda on em algum lugar e ficar, trabalhar, arrumar uma esposa e ficar sossegado..." (Participante 2).

"Você tá no trecho, não sabe a hora que vai almoçar... vocêpassa sede, não tem nada fácil..." (Participante 5).

\section{Vida no Trecho}

Esta categoria procurou mapear os relacionamentos que o "trecheiro" estabelece no modo de vida itinerante, compreendidos nas seguintes subcategorias: vínculos familiares, sobrevivência, sexualidade, as regras que se submetem e as rotas percorridas. De um modo geral, a vida no "trecho" é marcada pelo sofrimento, precariedade, indiferenciação, isolamento, desassistência e exclusão de todo contato com a rede social.

Vinculos familiares: embora a ruptura com a vida sedentária impulsiona o sujeito para o "trecho", a maioria ainda mantém algum contato com os familiares. Visitas esporádicas de pelo menos uma vez durante o ano, chamadas telefônicas a cobrar e, eventualmente, envios de cartas, são os principais meios utilizados de contatar com a família, apesar de alguns perderem completamente a comunicação devido a mudanças de endereços dos familiares. Exemplos:

"Eu fiquei mais ou menos... uns oito anos sem ver a minha mãe. E hoje eu vivo com minha mãe em termos, cada ano eu faço duas ou três visitas pra ela" (Participante 6). 
"De vez em quando eu telefono pra uma cunbada minha perguntando por eles. Quando eles confirmam a ligação a cobrar, né. Vai fazer um ano que eu não vejo eles [pais?”' (Participante 9).

"Perdi o contato com minha família... tem muitos deles que não sei nem o endereço. Alguns endereços velhos, já não moram mais, então fica difícil. Faz muito tempo que a gente não tem contato com a familia" (Participante 10).

Sobrevivência: a vida no "trecho", por todas as dificuldades de encontrar trabalho, leva o sujeito a pedit para sobreviver. A maioria encara qualquer tipo de trabalho quando encontra - os chamados "bicos" - sendo as árvores e os postos de gasolina, as principais referências para o abrigo diário. Exemplos:

"Eu peco uma ajuda, uma roupa, um calcado... Eu durmo embaixo de árvore, uma casa abandonada se achar..." (Participante 2).

"Se a gente achar um trabalho a gente far, só que às vezes é obrigado a pedir... então quer dizer, estamos matando a fome... Pra dormir, tem de chegar em posto de gasolina, compreendeu, porque hoje pode ver essas fazendas aí já não tem mais casa" (Participante 8).

"Qualquer servico que en posso fazer eu faço. Muitas vezes en peç pra não roubar porque se roubar, vai preso, né. Pra dormir, quando não acha posto de gasolina, a gente dorme embaixo de uma árvore mesmo" (Participante 9).

Sexualidade: as relações sexuais no trecho parecem ter pouca importância na vida desses sujeitos. Ela ocorre casualmente em certos casos e, em outros, ela é quase inexistente. Geralmente, os relacionamentos sexuais são mantidos com as mulheres do "trecho", porém, alguns sujeitos quando conseguem algum dinheiro, procuram as casas de prostituição à beira da estrada ou nos locai afastados da cidade. A preocupação de se proteger contra doenças sexualmente transmissíveis, também aparece nos relatos dos sujeitos. Exemplos:

"Nós encontra, só que nós não pega não... Mulher a gente encontra em qualquer lugar, só que a gente não mexe com esse tipo de coisa, perigoso, é arriscado, doenca..." (Participante 2).

"Eu tenho assim... relação com mulher quando tô no serviço, na boa, tendo meu dinheirinho, tem uns lugar que eu vou... em boate, esse negócio, mas mulher do trecho, não" (Participante 4).

"Não existe um relacionamento mais intimo... porque é o seguinte: no trecho, ninguém sabe quem é quem e o nosso país tá tão perdido, aids ou outras doenças venéreas que pode levar a pessoa à morte. Então eu me recuso disso..." (Participante 5).

Regras no trecho: parece não haver um conjunto de regras ou normas específicas entre os "trecheiros". A maioria relata que a única lei que existe entre eles é a individualidade, ou seja, o "cada um pra si", sempre respeitando as diferenças e limitações do outro. Preferem andar sozinhos ou, no máximo, em duplas para qualquer eventualidade na estrada. Quando se reúnem, casualmente, tudo é compartilhado sem restrições. Exemplos:

"Ah! rapaz a lei eu acho... quem tem que fazer é a gente mesmo... a nossa lei tem de ser um respeitar o outro... Quando eu penso uma coisa, o outro já não pensa isso aí, o motivo é esse aí, a lei quem tem que fazer é a gente mesmo" (Participante 4).

"Mas dentro do trecho, é uma desunião terrivel, é uma falta de consideração, é cada um pra si porque não existe essa lei pra um julgar o outro" (Participante 6).

"A lei é que ninguém pode pegar o que é dos outros... porque amanhã pode ser o contrário. Isso ai é uma coisa que... não pode épisar na bola com ninguém..." (Participante 9).

Rotas percorridas: as estratégias de sobrevivência utilizadas pelos sujeitos parecem girar em torno da procura de cidades que apresentam características bem semelhantes quanto à oferta de trabalho, tal como acontece com as cidades do norte do Paraná e todo o oeste do estado de São Paulo. Tal circularidade é explicada em função da existência, nessas localidades, de oferta de trabalho volante como o corte da cana, a colheita do café e os serviços braçais da agricultura de um modo geral. Essas regiões embora tenham introduzido em suas lavouras a mecanização da mão-de-obra, são percebidas pelos sujeitos como lugares ainda possíveis de obter algum tipo de ganho financeiro, apesar de apresentarem uma sazonalidade empregatícia. Exemplos:

“(...) de repente, tenho uma informação, né, de gente lá de Londrina (PR), que tem servico e tal e a gente vai lá ver se... Tentar a sorte, né. Eu tô pra irpra Maringá (PR), né.. de qualquer forma eu vou, né, vou de a pé e tal..." (Participante 7).

"(...) en venho vindo agora de Jataizinho (PR), passo direto, depois cheguei em Pongaí (SP), de lá, pra cá... Inclusive eu tô descendo aí pra Garça (SP) porque lá tem a colbeita do café. Eu vou daqui a alguns dias começar, né, tem carpição e tudo" (Participante 4).

"Iá passei em Bauru (SP) e lá tem uma serralheria e no final do ano, de junbo pra frente, também é bom de serviço, aí passo por lá. Passo também em Botucatu (SP), Ourinhos (SP), Assis (SP) e vou pra Londrina..." (Participante 3).

\section{Bloco II - Uso do Álcool}

As influências dos pais ou amigos na infância do sujeito, bem como as frustrações ocorridas no plano sócio-afetivo, aparecem como uma das principais causas que levam o sujeito a iniciar-se no uso de bebidas alcoólicas. No "trecho", o uso do álcool parece estar associado à necessidade de "esquecer problemas" do passado e evadir as sensações de angústias e conflitos em que vive frente à realidade. Para termos uma compreensão mais detalhada do uso do álcool por esses sujeitos, subdividimos esse tema em quatro subcategorias:

Início do consumo: as primeiras experiências com o álcool ocorrem no ambiente familiar do sujeito por influência, principalmente, do pai ou um parente próximo e, em geral, acontece por volta dos 10 aos 15 anos de idade. A roda de amigos aparece, também, como um dos possíveis motivos que levariam o sujeito a beber, talvez, como uma maneira de inserir-se no mundo adulto ou, quem 
sabe, provar sua masculinidade frente ao grupo. Exemplos:

"Ah! faz tempo. Eu bebo desde os 15 anos. Minha mãe é que bebe mais... en comecei a beber na casa da minha tia. Ela bebe até hoje, bebe bastante... eu bebo por livre e espontânea vontade mesmo. Bebo cerveja, pinga, o que vier eu bebo" (Participante 1).

"Eu comecei com uns 10 anos de idade. Meu pai também bebia... minha mãe é que bebia mais e eles bebiam era cachasa mesmo... Eu comecei no meio da molecada... que faria aquela fogueirinha na rua de casa...” (Participante 3).

"Olha meu primeiro contato com o álcool foi com 10 anos de idade... Eu me lembro que eu fui pra uma roca de amendoim...Então, foi justamente nessa roça que en acabei tomando bebida alcoólica. A partir dai, en comecei a gostar da bebida... conhecendo colegas em festinhas..." (Participante 11).

Motivos do uso do álcool: conforme a análise dos relatos, os motivos apontados para o uso do álcool no "trecho" estão associados à necessidade de esquecimento de frustrações do passado, principalmente, decorrentes da infidelidade da mulher na relação conjugal. Perdas significativas na vida do sujeito (morte dos pais, separação da esposa e dos filhos, por exemplo) e necessidades de encorajamento para vencer a timidez, também aparecem como importantes motivos para o uso do álcool na errância. Deste modo, devido à insuportabilidade de sua condição atual de vida (pobreza extrema, isolamento social, desamparo, etc.), o álcool parece atuar como um apaziguador desses conflitos. Exemplos:

"Mas no trecho, eu bebo é pra esquecer problemas porque o trecho

é duro, né, passa fome, monte de coisas, tem que pedir e com umas pingas na cabeça dá mais coragem..." (Participante 12).

"Desgosto demais na vida, não ter um lugar fixo pra ficar, então a gente bebe por causa disso... en peguei ela com um cara em cima de minha cama... Eu tomo um conhaquinho, uma cachasa pra gente esquecer os passado..." (Participante 2).

"No trecho eu bebo é pra ficar animado mesmo, pra sair na batalha. Bebo porque às vezes, não tenho coragem de falar uma coisa sem beber, aí já tomo duas e falo... então o motivo é esse, pra criar coragem e pedirpra comer..." (Participante 9).

Percepção da bebida: a maioria não admite o consumo abusivo do álcool e são categóricos ao afirmar que possuem absoluto controle sobre a bebida. Muitos acreditam que conseguem parar de beber e recorrem, às vezes, ao discurso religioso para explicar a abstinência. Essa "insinceridade" ou negação, embora não reconhecida pelo "trecheiro", é freqüentemente utilizada como um mecanismo de defesa frente às necessidades de conseguir um emprego fixo para a manutenção da própria sobrevivência. Quando perguntados se conseguiriam parar de beber, a maioria respondeu positivamente, como ilustra os seguintes exemplos:

"Ah! bicho, eu consigo, sabe por quê? É o seguinte: a gente tem que por na cabeça que bebida não dá futuro pra ninguém... Depois que en fiquei muito desgostoso é que en voltei a beber, já fiquei dois anos sem beber..." (Participante 4).

"Parar a gente pára. É que nem meu pai falou, é vergonha, né, e opinião porque bebida é doença, remédio mesmo não existe..." (Participante 9).

"Já consegui porque é Jesus. Jesus me esclareceu, me iluminou a mente, sabe, e tô vendo as coisas de outra forma... eu tô fora do álcool e não tô olhando pra trás..." (Participante 10).

Socialidade do álcool: a vida no "trecho", marcada por condições extremamente precárias, possibilita, temporariamente, o estreitamento da socialidade intermediada pelo uso da bebida. Entre os "trecheiros", ela é compartilhada sem restrições, sendo a aguardente de cana (cachaça), a mais consumida. As pequenas grupalizações em torno da bebida parecem provocar algumas desavenças entre eles, aumentando ainda mais a desconfiança e as restrições dos relacionamentos interpessoais, impulsionando, deste modo, o sujeito a escolher a solidão como companheira inseparável da estrada. Exemplos:

"Alguém carrega pinga, se um comprar uma garrafa de pinga, todo mundo toma na roda, que nem um prato de comida, se só tem aquele, todo mundo vai comer um pouco" (Participante 7).

"Eles brigam entre si porque cada pessoa tem uma natureza, tem uns que bebe e comesa a chorar, outros vai dormir... outros já vai brigar" (Participante 8).

"Quando você bebe com outros trecheiros, você faz uma rodinha e o copo sempre corre pro lado direito. Cada um toma um pouquinho e quando acaba aquela, faz uma vaquinha e se não tiver dinbeiro, sai à procura, vai pedir" (Participante 5).

\section{Perspectivas Futuras}

Apesar de todos os motivos apresentados pelos sujeitos para a ruptura com a vida sedentária (morte dos pais, falta de um lugar fixo para sua residência, desemprego, mão-de-obra desqualificada e desentendimentos com esposas e filhos), a grande maioria fomenta o sonho de voltar ao sedentarismo com intenção de reconstituir família, moradia e emprego fixos. Exemplos:

"Pretendo voltar, ser o que era antes e juntos com meus filhos ainda... Eu tenho vontade de ter uma esposa, mas é que é o seguinte: a primeira coisa é meus filhos, ter uma casinha, ficar com os meus filhos, juntos" (Participante 4).

“(...) quero ser feliz... procurar pelo objetivo, trabalhar, sei lá, tentar arrumar uma mulher de novo, certo, uma casa, uma família, construir uma familia, eu acho que isso é ser feliz... O trecho é uma ilusão" (Participante 3).

"Olha, meu sonho é voltar ao trabalho, como antes... seja ele qual for... Eu quero ter uma família, um lugar fixo pra ficar, é isso... Então o trecheiro é um objeto sem valor... minha vontade é voltar, sair desse trechão aí..." (Participante 10). 


\section{Discussão}

O fenômeno da errância parece estar associado a um complexo de fatores que modelam o mundo contemporâneo. A globalização, a flexibilização do trabalho, a informatização e automação da produção, a substituição da sociedade industrial pela de serviços, a virtualização da realidade, a dispersão, o individualismo, a aceleração do tempo e a expansão do espaço têm exercido um papel considerável na desterritorialização do sujeito e na sua impulsão para o nomadismo.

No entanto, um dos motivos marcantes em toda trajetória de vida desses indivíduos para se iniciarem no "trecho" foi o desemprego e a exigência de qualificação de mão-de-obra exigida atualmente pelo mercado Impossibilitados de concorrer num mercado de trabalho cada vez mais competitivo, gradativamente, são impulsionados para a marginalização social ficando desprovidos de qualquer referência social-psicológica.

Deste modo, os "trecheiros" parecem estar incluídos entre aqueles que Castel (1995/1998) considera como desfiliados da sociedade. Segundo o autor, a competitividade no mercado de trabalho, os baixos salários e o excesso de mão-de-obra especializada disponível acaba criando uma sociedade cada vez mais individualista e segregatória onde trabalhadores com pouca qualificação profissional são confinados a uma desfiliação social por não preencherem as novas exigências instituídas pela sociedade atual. À beira desse "abismo" social, são empurrados e condicionados a um individualismo negativo porque são declinados em termos de falta: falta de consideração, falta de seguridade, falta de bens garantidos e de vínculos estáveis.

Incapazes, portanto, de pertencerem à essa nova ordem social em que predomina o individualismo instituído pelo mercado, onde o indivíduo se apresenta como um ser moral, independente, autônomo e nãosocial, os "trecheiros" se enquadram como um se absolutamente desfiliado que só pertence a si mesmo, é o "bomem de ninguém", que não está inserido em coletivo algum. Conforme Castel (1995/1998), “(...) é um puro indivíduo e, por isso, completamente despossuído, individualizado a tal ponto, que está superexposto: desprende do tecido encorpado das relações de dependência e de interdependência que estruturam a sociedade." (p.597)

Nesse aspecto, segundo Merton (1968, citado por Snow \& Anderson, 1992/1998), a vida errante se caracteriza como uma tentativa de fugir da sociedade feita por aqueles a quem faltava a potência para competir na sociedade, pois, após repetidos fracassos no mundo social, os andarilhos renunciam tanto às metas da sociedade, quanto ao meio legítimo de alcançá-las, tornando-se indivíduos assocializados.

Além da questão do desemprego como um componente norteador de toda a trajetória de vida dos "trecheiros", outros motivos também associados a este aparecem como significativos para a deserção e a ruptura com o sedentarismo. Trata-se da morte dos pais e dos desentendimentos com esposas e filhos. Esses acontecimentos estão diretamente conectados com a questão da falta de empregos e pobreza, pois, à medida que as cobranças sociais vão pressionando o sujeito a arcar com o ônus da vida sedentária (aluguel, despesas domésticas, sustento dos dependentes, etc.) acaba por impulsioná-lo para a deserção e a errância, decorrendo a solidão e o isolamento no "trecho".

De fato, como mostram os resultados da presente pesquisa e como já salientaram Snow e Anderson (1992/ 1998), parece que a falta de apoio dos familiares é um dos fatores preponderantes para a ruptura do sujeito com o nicho social no qual está inserido. Ou seja, muitos indivíduos não têm uma família a quem se socorrer quando se acham desempregados, sem dinheiro e vitimados por cortes de benefícios.

Projetados, então, para uma individualização negativa, seu modo peculiar de vida na condição da errância é sustentado por esse individualismo absoluto onde o que impera é a lei do cada um para si, tanto nas relações interpessoais como nas outras relações estabelecidas no "trecho". Enfrentam numerosas situações de insegurança e de precariedade que se traduzem num cotidiano estremecido, feito de buscas inquietas para "se virar" no dia a dia. Embora situados nessa condição de extrema pobreza, a grande maioria mantêm, ainda, alguns contatos esporádicos com os familiares e fomenta o sonho de retornar ao sedentarismo. Esses dados coincidem com outros trabalhos realizados por Justo (1998) e Snow e Anderson (1992/1998).

Quanto às rotas percorridas, os "trecheiros" procuram circular por cidades com características semelhantes e que apresentem algumas perspectivas de trabalho temporário e sazonal. Nesse sentido, os "trecheiros" percorrem as mesmas cidades várias vezes ao ano em função da sazonalidade das colheitas e da oferta de trabalho. Esses resultados também estão presentes nos trabalhos de Justo (1998) e Snow e Anderson (1992/1998). Ambos os autores apontam que o meio de subsistência preferido tende a ser o trabalho remunerado e suas viagens são em grande parte determinadas por variações sazonais e regionais nos mercados de trabalho. Seja qual for a 
situação, sempre procuram restringir ao máximo suas relações interpessoais e se refugiam na solidão e na individualidade.

O uso do álcool na vida desses sujeitos parece iniciarse na infância estimulado pelo próprio meio familiar, principalmente pela influência do pai. A importância da roda de amigos aparece, também, como um dos fatores preponderantes para o início do consumo de bebidas alcoólicas, associado, talvez, à necessidade do sujeito impor sua masculinidade frente ao grupo na qual convive. Esses resultados confirmam os dados encontrados com certa freqüência na literatura que assinalam que a família e os amigos são um dos principais motivadores, na vida do indivíduo, para o início do consumo de bebidas alcoólicas (Araújo, 1995; Braga, 1977; Jorge \& Ferraz, 1981; Silva \& Cursino, 1995; Sonenreich, 1971).

Quanto aos fatores biogenéticos do alcoolismo, os dados dessa pesquisa não permitem considerar o consumo de álcool como um fator hereditário, mesmo porque foge das preocupações fundamentais desse trabalho. Entretanto, podemos argumentar, tal como assinala Vaillant (1995/1999), que famílias multiproblemáticas constituem para o sujeito a probabilidade maior de uma infância instável e infeliz onde a recorrência ao uso do álcool estaria associada à necessidade de refugiar das frustrações da realidade. Deste modo, o ambiente social do sujeito possa, talvez, contribuir também para o uso de bebidas alcoólicas, mesmo que não haja uma herdabilidade gênica para o alcoolismo. Poderíamos falar, então, de uma "predisposição ambiental" como propõe Cloninger (1987) e não somente os fatores genéticos como uma das grandes responsáveis na incidência do alcoolismo.

Parece haver, então, uma estreita vinculação entre problemas familiares e sociais com a anomia. Snyder (1954) já salientara que as desigualdades na estrutura social, contribuem para a conduta desviante do sujeito cuja recorrência ao uso do álcool estaria relacionada a busca de uma maior integração social. No caso da errância, problemas de relacionamento familiar parecem marcar toda a história de vida do sujeito, conforme podemos verificar nas entrevistas. Oriundos de famílias com baixo poder aquisitivo, sobrevivendo da mão-de-obra volante no campo onde o consumo de bebidas alcoólicas é bastante acentuado, as relações familiares são permeadas por discussões e desentendimentos entre seus membros agravados pelo alcoolismo, principalmente, do pai que desestrutura toda a organização familiar e acentua os comportamentos desviantes e anômicos dos demais familiares.

Psicologia: Reflexão e Crítica, 2000, 13(3), pp.529-538
No "trecho", os motivos para o uso do álcool são atribuídos pelos próprios sujeitos à necessidade de esquecer problemas e adquirir um maior encorajamento diante das condições precárias em que vivem. Ou seja, o passado promissor que a maioria dos sujeitos tiveram parece ser um peso insuportável a carregar no presente. O consumo de bebidas alcoólicas atuaria como um mecanismo de defesa e fuga frente às frustrações da realidade com a qual não conseguem lidar satisfatoriamente.

As necessidades de beber para adquirir maior encorajamento, assinalada no estudo de Braga (1977) com os mendigos, parece colocar-se também para os errantestrecheiros: tanto naquele como neste trabalho, a timidez e a falta de comunicabilidade estão presentes como obstáculos para a sobrevivência. Como a maioria precisa pedir para sobreviver e não tem coragem, o álcool é um recurso muito utilizado pelos sujeitos para a desinibição nessas condições.

Entretanto, o principal motivo que leva o indivíduo a utilizar o álcool no "trecho" é a necessidade de esquecer problemas, principalmente, problemas afetivos que inclui a infidelidade da mulher na relação conjugal. Snow e Anderson (1992/1998) também destacaram em seu trabalho que as desavenças conjugais contribuem para a ruptura com a vida sedentária. Conforme já foi assinalado, o passado promissor parece ser algo insuportável para o sujeito carregar consigo num presente aniquilador.

A importância da mulher na vida do sujeito parece aprisioná-lo no presente anônimo e passivo, tal como assinala Alonso-Fernandez (1991), fazendo predominar o sentimento de solidão decorrente da frustração afetiva. A traição da mulher aparece nas entrevistas como uma grande tragédia ocorrida na vida do sujeito, dando a impressão de ter sido um acontecimento mais importante do que outros também associados à sua deserção como a pobreza, o desemprego e a ausência de moradia. Dessa maneira, poderíamos pensar que a mulher ocupa o lugar central de onipotência na vida do sujeito, pois, para ele a figura da mulher representa a fonte detentora de "objetos preciosos" e submete o indivíduo aos seus caprichos. Segundo Melmam (1992), “(...) a tolerância notável da mulher é conhecida: ela sabe que ocupa, na economia psíquica do marido, o lugar central, de onipotência, fixando-o em uma posição de pedinte pueril, mesmo que ele seja violento, ou barulhento." (p.19)

Embora a socialidade da bebida no "trecho" possibilita, temporariamente, o estreitamento das relações interpessoais, a maior parte dos sujeitos procuram sempre o isolamento e o anonimato devido a desconfianças provocadas pelas desavenças que surgem após a ingesta 
alcoólica. Esses dados comprovam a hipótese de Snow e Anderson (1992/1998) ao destacar que os andarilhos recusam a oportunidade de se unir a um grupo para beber.

A grande maioria dos sujeitos também nega o consumo abusivo da bebida e, talvez, utilizam a insinceridade como mecanismo de defesa em tais situações (Van Kolck e cols., 1991). Todos os sujeitos de nossa pesquisa afirmavam que bebiam pouco e com certo controle antes das entrevistas e que decidiram abandonar o álcool após entrevistados. Embora não tendo sido verificado, posteriormente, se tal decisão declarada de abandonar o uso do álcool foi ou não efetivada pelos sujeitos, o fato de todos terem feito essa afirmação, e de modo repentino, sugere a ocorrência da conduta de "insinseridade".

Motivados por ideais de grandeza onde há o predomínio da fantasia, as perspectivas futuras do sujeito estão relacionadas ao sonho de retornar ao sedentarismo ou de ainda saírem vitoriosos, embora sua atual condição de vida não proporcione algumas possibilidades para tamanha idealização. Nesse aspecto, podemos verificar que os "trecheiros", embora sejam sujeitos tipicamente marcados pela exclusão e adversidades, mantêm certa esperança ou ideais de reconstituir família, moradia e empregos fixos. Esse dado contrasta com aqueles encontrados por Alonso-Fernandez (1991) que coloca o alcoolista numa situação de desesperança marcada pela indiferença e pelos fantasmas de insucessos anteriores causados pela ausência de tolerância às frustrações. É necessário, no entanto, ponderar que essas duas pesquisas não são diretamente comparáveis porque se diferenciam quanto à população e amostragem.

Essencialmente, poderíamos finalizar esse tópico de discussões salientando que parece haver uma interligação entre o desemprego, a falta de apoio familiar, a infidelidade, o alcoolismo e a vida errante. Muitos dos "trecheiros" estão nessa condição de vida porque não possuem rede alguma de apoio familiar viável a qua recorrer quando são vitimados por algum outro infortúnio, como falta de emprego potencializada pela desqualificação de sua mão-de-obra pelo exigente mundo contemporâneo onde o uso de bebidas alcoólicas aparece como uma maneira de apaziguar esses conflitos decorrentes da frustração afetiva a que estão subordinados.

\section{Referências}

Alonso-Fernández, F. (1991). A personalidade prealcoolica. Temas, 21(40/ 41), 19-30.

Araújo, L. B. (1995). O uso do álcool como ritual de passagem da adolescência para a idade adulta: Alguns aspectos indicativos para programas de prevenção ao abuso do álcool [Resumo]. Em Sociedade Brasileira de Psicologia (Org.), Resumos de comunicaçöes cientificas, XXV Reunião Anual de Psicologia (p. 41). Ribeirão Preto: SBP.

Bardin, L. (1979). Análise de conteúdo. Lisboa: Edições 70.

Bertolote, J. M. (1997). Problemas sociais relacionados ao consumo de álcool. Em S. P. Ramos \& J. M. Bertolote (Orgs.), Alcoolismo boje (pp. 31-138). Porto Alegre: Artes Médicas.

Braga, M. C. (1977). Caracterização de um grupo de alcoólicos na área da mendicancia. Dissertação de Mestrado não-publicada. Departamento de Serviço Social, Pontifícia Universidade Católica do Rio de Janeiro, Rio de Social, Pon
Janeiro, RJ.

Janeiro, RJ.
Castel, R. (1998). As metamorfoses da questão social: Uma crônica do salário (I. D. Poleti, Trad.). Petrópolis, RJ: Vozes. (Original publicado em 1995) Castro, H. M. \& Silva Filho, W. M. (1993). Avaliação do programa de atenção ao alcoolista no município de Carapicuíba. Temas, 23(46), 141-175. Cloninger, C. R. (1987). Neurogenetic adaptative mechanisms in alcoholism. Science, 136, $410-416$

Jorge, M. R. \& Ferraz, M. P. T. (1981). A percepção do alcoólatra do que o leva ao alcoolismo e à internação. Boletim de Psiquiatria, 14(3), 132-137.

usto, J. S. (1998). Errâncias e errantes: Um estudo sobre andarilhos de estrada. Em J. S. Justo \& R.Y. Sagawa (Orgs.), Rumos do saber psicológico (pp. 125-139). São Paulo: Arte \& Ciência.

Kolck, O. L. V., Tosi, S. M. V. D. \& Pelegrini, T. F. (1991). Auto-imagem em alcoólicos crônicos. Temas, 21(42), 374-382.

Melman, C. (1992). Alcoolismo, delinguiência e toxicomania: Uma outra forma de gozar. São Paulo: Escuta.

Melman, C. (1993). Alcoolismo e toxicomania: Uma abordagem psicanalítica. Temas, 23(45), 41-49.

Silva, R. C. \& Cursino, E. A. (1995). O consumo de bebidas alcoólicas por adolescentes: Dados sobre o consumo e concepções sobre o uso [Resumo]. Em Sociedade Brasileira de Psicologia (Org.), Resumos de comunicaçôes científicas, XXV Reunião Anual de Psicologia (p. 179). Ribeirão Preto: SBP.

Snow, D. \& Anderson, L. (1998). Desafortunados: Um estudo sobre o povo da rud (S. Vasconcelos, Trad.). Petrópolis, RJ: Vozes. (Original publicado em 1992)

Snyder, C. (1954). Ebriedad, alcoholismo y anomie. Em M. B. Clinard (Org.), Anomia y conducta desviada (pp. 181-197). Buenos Aires: Paidós. Sonenreich, C. (1971). Contribuicão para o estudo da etiologia do alcoolismo. São Paulo: Editora do autor.

Vaillant, G.E. (1999). A bistoria natural do alcoolismo revisitada (B. S. C. da Cunha \& J. A. L. dos Santos, Trads.). Porto Alegre: Artes Médicas. (Original publicado em 1995)

Sobre os autores:

Eurípedes Costa do Nascimento é Psicólogo, formado pela Universidade Estadual Paulista (UNESP) e foi bolsista do CNPq.

José Sterza Justo é Psicólogo, Doutor em Psicologia Social pela Pontifícia Universidade Católica de São Paulo (PUC), Professor no Programa de Pós-Graduação em Psicologia e Sociedade, na Universidade Estadual Paulista em Assis (UNESP).

Recebido em 06.09.1999 Primeira revisão em 08.10 .1999 Segunda revisão em 06.12.1999 Aceito em 10.01.2000 